\title{
PENGARUH FAKTOR-FAKTOR AKUISISI TERHADAP ABNORMAL RETURN (STUDI PADA PERUSAHAAN AKUISITOR DI BEJ ANTARA TAHUN 1992 SAMPAI 1997)
}

\author{
Ali Muktiyanto \\ Universitas Terbuka
}

\begin{abstract}
The objective of this study are (1) to examine the change the abnormal returns pre and post acquisition, (2) to examine the influence of acquisition factors: $Q$ ratio (Tobin's $Q$ ratio), relative size between bidder and target acquisition (size), reaction target management (hostile or fiendly/HF), choice of investment financing/COI), number of bidder acquisition (number of bidder/NB) and asymmetric information (Al), on the companies' abnormal returns either simultaneously or partially, and (3) to examine the influence acquisition factors on the abnormal returns in case of internal and external acquisition.

By analyzing financial statement of 20 bidders and 40 target conducted acquisition at Bursa Efek Jakarta between 1992 and 1997, the result of the study shows that (1) the companies abnormal returns have positive performance, (2) the acquisition factors in both simultaneously and partially have positive influence on the abnormal returns, and (3) there is a different influence of acquisition factors on the abnormal returns between internal acquisition and those of external acquisition.
\end{abstract}

Key words: acquisition, abnormal return, bidder, target

PENDAHULUAN

Persaingan dalam dunia bisnis dewasa ini mendorong perusahaan-perusahaan yang sedang tumbuh dan berkembang untuk mengambil langkah-langkah yang dapat mengamankan posisinya. Salah satu langkah yang dapat pula menjadi cara untuk menyelamatkan usaha dari kebangkrutan adalah restrukturisasi usaha dalam bentuk merger, konsolidasi dan akuisisi (MKA).

Penulis memandang bahwa mencermati akuisisi tidak hanya sekedar mengetahui perbedaan kinerja sebelum dan sesudah akuisisi saja. Justru yang lebih lebih menarik dan merupakan kelanjutan dari penelitianpenelitian sebelumnya adalah mengkaji faktor-faktor yang menjadikan akuisisi mampu menghasilkan sinergi dan hal-hal lain yang diharapkan. Selanjutnya barulah faktor-faktor yang mendorong munculnya perubahan harga saham yang abnormal (abnormal stock price changes).

Servaes dalam artikelnya yang bertajuk "Tobin's $Q$ and Gains from Takeovers" termuat dalam Journal of Finance Vol. LXVL No. 1 March 1991, hal 409-419, mengemukakan lima faktor yang mempengaruhi perubahan harga saham. Pertama, Rasio Q (Tobin's Q Ratio); Kedua, perbandingan relatif perusahaan yang mengakuisisi dan yang diakuisisi (Relative Size); Ketiga, reaksi dari manajemen perusahaan yang akan diakuisisi (Hostile or Friendly/HF); Keempat, bentuk pembiayaan (Choice of Investment /COI); dan kelima jumlah peminat yang akan mengakuisisi (Number of Bid- 
der/NB). Selain itu Myers and Majluf (1984) dalam Amihud (1990) mengamati faktor informasi asimetris (Asymmetrics Information/Al).

Berdasarkan hal-hal yang telah disebutkan diatas, maka faktorfaktor yang mempengaruhi kinerja akuisisi menjadi hal yang sangat menentukan keberhasilan akuisisi. Akuisisi tidak lagi hanya sekedar menggabungkan dua perusahaan atau lebih atau sekedar mengambil alih kepemilikan perusahaan, tetapi merupakan satu keputusan yang strategis yang didasarkan atas pertimbangan-pertimbangan yang matang.

\section{IDENTIFIKASI DAN PERUMUSAN MASALAH}

Faktor-faktor yang harus dipertimbangkan dalam akuisisi antara lain adalah sifat akuisisi itu sendiri, akuisisi internal ataukah akuisisi eksternal; pembiayaan transaksi akuisisi, dibiayai dengan tunai (kas), hutang, ataukah dengan pertukaran saham; sikap dari manajemen perusahaan yang akan diakuisisi (target), menerima ataukah menolak; ukuran relatif target dengan yang mengakuisisi (bidder); jumlah peminat yang akan mengakuisisi; dan penilaian atas nilai perusahaan yang dipengaruhi informasi asimetris (undervalue ataukah overvalue); serta rasio Q perusahaan yang melakukan akuisisi. Faktor-faktor tersebut berdasarkan penelitianpenelitian sebelumnya berpengaruh terhadap abnormal return perusahaan.

Berdasarkan identifikasi masalah tersebut maka masalah yang diteliti dapat dirumuskan sebagai berikut.

1. Bagaimana abnormal return sebelum dan setelah akuisisi

2. Sejauh mana faktor-faktor akuisisi, baik secara simultan maupun secara parsial mempengaruhi abnormal return.

3. Sejauh mana perbedaan pengaruh faktor-faktor akuisisi terhadap abnormal return kelompok akuisisi internal dan akuisisi eksternal.

\section{TINJAUAN PUSTAKA}

Tujuan utama operasi perusahaan adalah memaksimalkan nilai perusahaan (maximization value of firm) yang pada akhirnya adalah memaksimalkan kemakmuran pemegang kepentingan (maximization wealth of stakeholders). Pemegang kepentingan di sini adalah pemegang saham, manajemen, karyawan dan masyarakat. Tingkat pencapaian terhadap tujuan ini dapat dilihat dari kinerja yang dihasilkan.

Perusahaan dituntut mencari dan menemukan strategi-strategi lain yang mampu menjawab tujuan tersebut. Seperti dikemukakan oleh llya (1994:3), setidaknya terdapat tiga strategi yang dapat dilakukan yaitu:

1. Mengadakan ekspansi dari usaha yang telah ada (internal business expansion), tanpa melihat unit-unit usaha di luar organisasi perusahaan. 
2. Membuat perusahaan atau proyek baru.

3. Mengadakan penggabungan badan usaha (internal business expansion), yang dapat berbentuk konsolidasi, merger dan akuisisi (MKA).

Berkenaan dengan pendefinisian merger dan akuisisi menurut "The World Book encyclopedia" (1989), merger didefinisikan sebagai berikut: "merger is the combination of two or more independent companies into a single corporation. In most merger, a firm acquires the assets and liabilities of a smaller enterprise by purchasing its capital stock. It then takes over the operation of the smaller firm and drops that firm's name. In some mergers, firms of similar size joint to form an entirely new corporation" (PDBI, 1995:22).

Secara khusus Hogarty (1972) dalam Havinson (1996) mengemukakan bahwa suatu merger dan akuisisi dinyatakan sukses artinya ada sinergi apabila terjadi peningkatan nilai bagi pemegang kepentingan (maximization wealth of stakeholders, yang dicerminkan oleh laba per lembar saham) dan bagi manajemen dengan kata lain terjadi perubahan kinerja yang positif. Dalam jangka pendek, sekitar waktu kejadian (even time) guna melihat efek akuisisi dapat dilihat dari perubahan abnormal return. Amatan terhadap abnormal return dilakukan dengan melihat data saham harian dalam waktu sekitar pengumuman akuisisi. Penelitian hal tersebut antara lain dilakukan oleh Jensen and Ruback (1983) dengan mengukur abnormal return sebagai efek ekonomi dari pengambilalihan (1983:597).

Lebih lanjut Jensen and Ruback (1983) mengatakan "abnormal return are measured by difference between actual and expected stock return. The expected stock return is measured conditional on the realized return on a market index to take account of the influence of market wide events on the returns of individual securities" (1983:597). Biasanya analisis mengenai abnormal return berkisar saat pertama pengumuman merger dan akuisisi kepada publik.

Havinson (1966) menyimpulkan dari sudut pandang perusahaan yang mengakuisisi tahun 1990-1992, bahwa merger dan akuisisi belum dapat meningkatkan nilai bagi shareholders dan manajemen apabila ditinjau dari return saham. Hal ini senada dengan pernyataan bahwa merger dan akuisisi menghasilkan negative returns (Dodd(1980) dalam Jensen and Ruback (1983)) dan sesuai pula dengan hipotesa bahwa merger bagi pengakuisisi merupakan investasi net present value (NPV) negatif.

Pada sisi lain llya (1984) menyimpulkan bahwa kinerja perusahaan setelah akuisisi lebih baik dibandingkan sebelum akuisisi. Dengan kata lain, terbukti bahwa dampak akuisisi menghasilkan sinergi bagi per- 
usahaan-perusahaan go public yang melakukan akuisisi (1994:118). Ini sejalan dengan penelitian Asquith and Eckbo (1983) dalam Jensen and Ruback (1983) untuk satu hari sebelum dan saat pengumuman merger dan akuisisi, menyimpulkan adanya kecenderungan abnormal return yang positif meskipun tidak signifikan. Ini sejalan dengan lima penelitian terpilih dalam Jensen and Ruback (1983), (Asquith: 1983), Eckbo (1983), Asquith, Broner and Mullins (1983), Malesta (1983) dan Wier (1983) mengenai abnormal return untuk akuisitor menunjukkan bahwa merger merupakan investai NPV nol (zero). Keberagaman kesimpulan penelitian terdahulu menunjukkan adanya sesuatu yang menarik untuk dikaji.

Dengan demikian menganalisis sinergi yang muncul dari merger dan akuisisi tidak hanya sekedar mengetahui kinerja sebelum dan sesudah akuisisi saja, namun juga memahami dan menelaah faktor-faktor yang mempengaruhinya. Beranjak dari penelitian Servaes (1991), Lang, Stulz and Walking-LSW (1989), mengenai hubungan antara pendapatan, gain from takeover, dengan rasio Q, penulis menduga terdapat beberapa faktor yang berkaitan dengan abnormal return. Pertama adalah rasio Q (LSW: 1989; Servaes: 1991); kedua adalah ukuran relatif perusahaan yang akan diakuisisi dan yang mengakuisisi (Jarrel and Poulsen :1989, Servaes: 1991); ketiga, reaksi manajemen perusahaan yang akan diakuisisi (Jensen and Ruback:1983, Servaes:1991); keempat, bentuk pembiayaan (form of payment) ((Travlos: 1987, Asquith, Bruner and Mullins: 1987, Servaes: 1991); kelima jumlah peminat yang akan mengakuisisi (number of bidder) dan keenam informasi asimetris (Brown and Ryngaert: 1991). Selain faktor lainnya misalnya pajak (Brown and Ryngaert: 1991).

Hasil Penelitian-penelitian sebelumnya dapat dikemukakan di sini sebagai berikut:

1. Rasio W perusahaan yang mengakuisisi dan yang diakuisisi mempunyai pengaruh signifikan terhadap pendapatan dari pengambilalihan (gains from takeovers) (LSW: 1989, Servaes: 1991).

2. Bentuk pembiayaan (choice of investment) menentukan dalam tercapainya abnormal return yang positif (Peterson and Peterson (1990), Amihud, Baruch and Travlos (1990), Servaes (1991).

3. Informasi asimetris (Asymmetries Information) merupakan satu hal yang penting dalam penentuan langkah-langkah dalam strategi akuisisi terutama dalam hal pembiayaan pengambilalihan (Myer and Majuf (1984), Brown and Ryngaert (1991).

4. Reaksi manajemen perusahaan yang akan diakuisisi (reaction/opposition of management target) merupakan hal yang dapat menaikkan atau menurunkan total return dari aktivitas pengambilalihan (Kummer and Hoffmeister (1978), Dodd (1980) dalam Jensen and Ruback (1983)). 
5. Ukuran relatif dari target dan bidder terkait pula dengan Rasio Q, dimana kinerja dari merger dan akuisisi setidaknya dapat tercapai umumnya jika ukuran target lebih kecil dibandingkan dengan bidder. Adapun terhadap jumlah peminat yang akan mengakuisisi (number of bidder), dimana jika peminat lebih dari satu, return target akan meningkat, sebaliknya return bidder lebih kecil ketika banyak pesaing, namun total return lebih besar (Servaes: 1991).

Pertimbangan penggunaan abnormal return seputar tanggal pengumuman sebagai indikator kinerja perusahaan didasarkan pertimbangan bahwa perubahan harga saham sekitar pengumuman merger dan akuisisi mudah untuk diamati, tidak harus menunggu dikeluarkannya laporan keuangan.

\section{HIPOTESIS}

Berdasarkan paparan yang disampaikan sebelumnya, maka dikemukakan hipotesis penelitian sebagai berikut:

1. Terdapat perubahan abnormal return setelah akuisisi.

2. Terdapat pengaruh faktor-faktor akuisisi, baik secara simultan maupun secara parsial terhadap abnormal return.

3. Pengaruh faktor-faktor akuisisi terhadap abnormal return berbeda antara akuisisi internal dan akuisisi eksternal.

\section{OBJEK DAN METODE PENELITIAN}

\section{Objek Penelitian}

Penelitian ini dilakukan pada emiten di Bursa Efek Jakarta (BEJ) yang melakukan akuisisi dari tahun 1994 sampai dengan 1995. Pengamatan dilakukan atas abnormal return akuisitor, selanjutnya dijadikan sebagai variabel terikat (dependent variable) dan faktor-faktor akuisisi (acquisition factors), selanjutnya dijadikan sebagai variabel bebas (independent variables).

Unsur variabel bebas tersebut adalah Rasio $Q$ (Tobin's $Q$ ratio), ukuran relatif perusahaan yang mengakuisisi dan diakuisisi (Relative Size), reaksi dari manajemen perusahaan yang akan diakuisisi (Hostile or Friendly/HF), pilihan bentuk pembiayaan (Choice of Investement Financing/COI), jumlah peminat yang akan mengakuisisi (Number of Bidder/NB) dan informasi asimetris (Asymmetrics Information/Al).

\section{Metode Penelitian}

Penelitian ini menggunakan disain penelitian sensus. Selanjutnya dilakukan deskripsi dan verifikasi terhadap jawaban masalah yang merupakan hasil pemikiran rasional di mana kebenarannya bersifat sementara 
melalui keseluruhan populasi. Data yang digunakan dalam penelitian ini adalah data primer dan data sekunder. Teknik pengumpulan data dilakukan melalui data primer yang diperoleh langsung dari perusahaan-perusahaan yang melakukan akuisisi yang menjadi target populasi dan dari BEJ. Pengumpulan data dilakukan secara polling dari laporan keuangan per 31 Desember. Data abnormal return seputar hasil pengumuman dan faktorfaktor akuisisi diperoleh sebagian besar dari BEJ. Data sekunder diperoleh secara polling dari BEJ, Biro Pusat Statistik, dan kepustakaan yang terkait dengan data dan kajian teoritis.

Metode analisis dilakukan dengan analisis deskriptif terhadap variabel-variabel penelitian, terutama variabel abnormal return. Guna menjawab dan menganalisis permasalahan sekaligus hipotesis nomor satu maka digunakan analisis rasio atas abnormal return sebelum dan sesudah akuisisi. Hasil analisis ini kemudian dibandingkan dan dilakukan analisis deskriptif.

Abnormal return dihitung sebagai kumulatif prediksi kesalahan model pasar (market model) dari 360 hari (12 bulan) sebelum dan 360 hari (12 bulan) sesudah pengumuman pengambilalihan. Perhitungan cummulative abnormal return dilakukan dengan melihat return saham setahun sebelum dan setahun setelah akuisisi ( $\mathrm{t}-12$ dan $\mathrm{t}+12)$.

Seperti dikemukakan oleh Jensen and Ruback (1983) bahwa abnormal return merupakan selisih antara tingkat keuntungan yang sebenarnya dengan tingkat keuntungan yang diharapkan. Pendapatan tersebut dirumuskan dengan:

$$
A R_{i, t}=R_{i, t}-E\left[R_{i t}\right]
$$

$\mathrm{AR}_{\mathrm{i}, \mathrm{t}}=$ abnormal return sekuritas ke i pada periode peristiwa ke-t

$\mathrm{R}_{\mathrm{i}, \mathrm{t}} \quad=$ return sesungguhnya yang terjadi untuk sekuritas ke-i pada periode peristiwa ke-t

$E\left[R_{i t}\right]=$ return ekspektasi sekuritas ke-i untuk periode peristiwa ke-t

Berdasarkan kerangka pemikiran, cummulative abnormal return (CAR) merupakan fungsi dari faktor-faktor akuisisi. Secara matematis dapat ditulis model yang merupakan modifikasi model yang dikemukakan Servaes (1991), sebagai berikut:

\section{$C A R=f($ Rasio $Q$, Size,$H F$, COI, NB, Al $)+\varepsilon$}

Model regresi ini diestimasi dengan regresi linier berganda yang dinotasikan sebagai berikut:

$$
\begin{aligned}
& \quad \pi=\beta_{0}+\beta_{1} \text { Rasio } \mathrm{Q} \text { Bidder }+\boldsymbol{\beta}_{2} \text { Size }+\beta_{3} \mathrm{HF}+\boldsymbol{\beta}_{4} \mathrm{COI}+\boldsymbol{\beta}_{5} \mathrm{NB}+\boldsymbol{\beta}_{6} \mathrm{AI}+\varepsilon \\
& \quad=\mathrm{CAR} \\
& \text { Rasio Q Bidder = rasio Q perusahaan yang akan mengakuisisi }
\end{aligned}
$$


Size = relative size, perbandingan ukuran dari target kepada bidder

$\mathrm{HF} \quad=$ reaksi manajemen target, hostile atau friendly

$\mathrm{COI}=$ bentuk pembiayaan, kas atau lainnya

NB = jumlah peminat yang akan mengakuisisi, multiple atau single

Al = informasi asimetris, undervalue atau overvalue

$\varepsilon \quad=$ variabel lain di laur variabel yang diteliti

$\beta_{0} \quad=$ intersep

$\beta_{1}$ sampai dengan $\beta_{6}=$ koefisien regresi

Persamaan regresi berganda di atas digunakan untuk menjawab dan menganalisis hipotesis nomor 2 yaitu terdapat pengaruh faktor-faktor akuisisi, baik secara simultan maupun secara parsial terhadap profitabilitas dan abnormal return.

Pengujian hipotesis nomor 3 menggunakan model regresi berganda yang sama dengan model regresi di atas dengan menambahkan dummy variabel (Gujarati, 1995:263), untuk membedakan pengaruh antara akuisisi internal dan akuisisi eksternal sebagai berikut:

$\pi=\beta_{0}+\beta_{1}$ Rasio Q Bidder $+\beta_{2}$ Size $+\beta_{3} \mathrm{HF}+\beta_{4} \mathrm{COI}+\beta_{5} \mathrm{NB}+\beta_{6} \mathrm{Al}+$ $\beta_{7}$ Rasio $Q$ Bidder Internal $+\beta_{8}$ Size Internal $+\beta_{9} \mathrm{HF}$ Internal $+\beta_{10} \mathrm{COI}$ Internal $+\beta_{11} \mathrm{NB}$ Internal $+\beta_{12} \mathrm{Al}$ Internal $+\beta_{13}$ Rasio $Q$ Bidder eksternal $+\beta_{14}$ Size eksternal $+\beta_{15} \mathrm{HF}$ eksternal $+\beta_{16} \mathrm{COI}$ eksternal + $\beta_{17} \mathrm{NB}$ eksternal $+\beta_{18} \mathrm{Al}$ eksternal $+\varepsilon$

Untuk mengetahui perbedaan antara akuisisi internal dan eksternal maka ditambahkan dummy variabel. Koefisien $\beta_{7}$ hingga $\beta_{12}$ dicari dengan memasukkan nilai 1 untuk akuisisi internal, dan diberi nilai 0 jika akuisisi eksternal. Koefisien $\beta_{13}$ hingga $\beta_{18}$ dicari dengan memasukkan nilai 1 untuk akuisisi eksternal, dan diberi nilai 0 jika akuisisi internal.

Perhitungan adanya analisis varian serta regresi digunakan bantuan perangkat lunak komputer program SPSS 7,5 dan Microsoft Excell serta disajikan dalam bentuk tabel-tabel.

\section{HASIL PENELITIAN}

Data yang digunakan dalam penelitian ini adalah "Polling Data" sebanyak 20 perusahaan pengakuisisi dengan 40 perusahaan yang diakuisisi, yang tercatat sebagai emiten di BEJ dari tahun 1994 sampai dengan 1995. Data berupa laporan keuangan dan pendukung lainnya yang ada pada Indonesian Capital Market Directory dari dua tahun sebelum akuisisi (1992) sampai dua tahun setelah akuisisi (1997). Data lainnya bersumber dari laporan-laporan yang dikeluarkan oleh BAPEPAM dan BEJ. Informasi lainnya berasal dari instansi-instansi terkait lainnya. 
Jumlah variabel penelitian adalah 7 (tujuh) variabel, terdiri dari 1 (satu) variabel terikat dan 6 (enam) variabel tidak terikat (bebas) yang berfungsi sebagai variabel eksplanatori. Variabel terikat tersebut adalah Cummulative Abnormal Return (CAR). Enam variabel bebas lainnya adalah Rasio Q (Tobin Q ratio's), ukuran relatif perusahaan yang mengakuisisi dan diakuisisi (Size), reaksi dari manajemen perusahaan yang akan diakuisisi (Hostile or Friendly (HF), pilihan bentuk pembiayaan (Choice of Investement Financing/COI), jumlah peminat yang akan mengakuisisi (Number of Bidder/NB) dan informasi asimetris (Asymmetrics Information/Al).

Berdasarkan stratifikasi populasi akuisisi, 90\% akuisisi bersifat internal, sisanya (10\%) eksternal. Transaksi akuisisi yang berbentuk horisontal berjumlah $70 \%$, sisanya berbentuk vertikal dan konglomerasi masing-masing (15\%). Adapun sumber pembiayaan 70\% dengan saham, 17,5\% kas dan 12,5\% hutang. 87,5\% transaksi harus dilalui dengan hostile dan sisanya (12.5\%) friendly. Sebanyak $90 \%$ transaksi akuisisi hanya mengundang satu peminat (single bidder) dan sisanya (10\%) multiple bidder. Akhirnya 30\% perusahaan pengakuisisi dinilai di pasar undervalue dan sisanya overvalue (70\%). Lebih jelas dapat dilihat pada Tabel 1 berikut ini.

Tabel 1: Stratifikasi Populasi Akuisisi

\begin{tabular}{|l|l|l|}
\hline \multicolumn{1}{|c|}{ Faktor akuisisi } & \multicolumn{1}{|c|}{ Stratifikasi } \\
\hline Sifat & Internal & 90.0 \\
& Eksternal & 10.0 \\
\hline Bentuk & Horisontal & 70.0 \\
& Vertikal & 15.0 \\
& Konglomerasi & 15.0 \\
\hline Sumber Dana & Saham & 70.0 \\
& Kas & 17.5 \\
& Hutang & 12.5 \\
\hline Reaksi Manajemen Target & Hostile & 87.5 \\
& Friendly & 12.5 \\
\hline Jumlah Peminat & Multiple Bidder & 90.0 \\
& Single Bidder & 10.0 \\
\hline Informasi asimetris & Undevalue & 30.0 \\
& Overvalue & 70.0 \\
\hline
\end{tabular}

Sumber : BEJ, data diolah kembali, 2000

PEMBAHASAN

Perubahan Abnormal Return setelah Akuisisi

Melalui pengamatan dan penganalisisan perubahan Cummulative Abnormal Return (CAR) 12 bulan sebelum dan 12 bulan setelah akuisisi dapat diketahui perubahan abnormal return perusahaan setelah akuisisi. Berdasarkan hasil analisis CAR, sebelum akuisisi rata-rata CAR 
perusahaan lebih kecil dari rata-rata CAR setelah akuisisi $(-0.0736$ $<0.0839)$. Berarti telah terjadi kenaikan CAR sebesar 0.01575 dari sebelum akuisisi.

Tabel 2. Cummulative Abnormal Return Sebelum dan Sesudah Akuisisi

\begin{tabular}{|l|l|r|r|r|}
\hline \multirow{2}{*}{ No } & \multicolumn{1}{|c|}{ Emiten } & \multicolumn{3}{c|}{ Cummulative abnormal return } \\
\cline { 3 - 5 } & & \multicolumn{1}{c|}{$\mathbf{t}-1$} & \multicolumn{1}{c|}{$\mathbf{t}$} & \multicolumn{1}{c|}{$\mathbf{t + 1}$} \\
\hline 1 & Bakrie Finance Corp. & -0.3992 & 0.0259 & 0.3733 \\
\hline 2 & Gajah Surya Multi Finance & -0.8668 & -0.1440 & 1.0108 \\
\hline 3 & Pakuwon Jati & -0.2162 & -0.0992 & 0.3154 \\
\hline 4 & Lippo Land Development & 0.0097 & 0.0471 & -0.0568 \\
\hline 5 & Bakrie \& Brothers & -0.1524 & 0.0219 & 0.1305 \\
\hline 6 & Bank Niaga & 0.0587 & 0.0617 & -0.1205 \\
\hline 7 & Igar Jaya & -0.0276 & 0.1161 & -0.0885 \\
\hline 8 & Darya Varia Laboratoria & 0.0801 & -0.0620 & -0.0176 \\
\hline 9 & Semen Gresik (Persero) & 0.3065 & 0.2293 & -0.5358 \\
\hline 10 & Bakrie Finance & -0.2005 & -0.0171 & -0.1196 \\
\hline 11 & Ometraco Corporation & -0.7454 & -0.0514 & 0.7968 \\
\hline 12 & Bank Danamon & 0.3968 & -0.1726 & -0.2242 \\
\hline 13 & Sumalindo Lestari Jaya & -0.4090 & -0.0130 & 0.4220 \\
\hline 14 & Alumindo Perkasa & 0.0155 & 0.2659 & -0.2813 \\
\hline 15 & Jaya Rela Property & 0.3399 & 0.0273 & -0.3399 \\
\hline 16 & Indofood Sukses Makmur & 0.3772 & -0.0988 & 0.0392 \\
\hline 17 & Evershine Tex & -0.4059 & 0.0360 & 0.3698 \\
\hline 18 & Aneka Kimia Raya & 0.7358 & -0.0610 & -0.6746 \\
\hline 19 & Tira Austenite & -0.6530 & 0.0618 & 0.5912 \\
\hline 20 & K.I. Jababeka & 0.2831 & 0.0380 & 0.0868 \\
\hline Jumlah & -1.4727 & 0.2119 & 1.6770 \\
\hline Rata-rata & -0.0736 & 0.0106 & 0.0839 \\
\hline
\end{tabular}

Sumber: BEJ tahun 1993-1998, data diolah kembali, 2000

Hasil ini menunjukkan bahwa sinergi yang diharapkan dari akuisisi atas return perusahaan dapat dicapai. Hasil ini mendukung hipotesa yang dikemukakan oleh Asquith and Eckbo (1983) dalam Jensen and Ruback (1983), yaitu akuisisi merupakan investasi NPV yang positif. Dengan demikian tujuan akuisisi untuk meningkatkan nilai saham bagi stakeholders dapat dicapai. Peningkatan abnormal return perusahaan dapat dijelaskan pula sebagai implikasi terangkatnya nilai saham perusahaan yang diakuisisi seiring dengan peningkatan nilai saham akuisitor yang sebelumnya telah dinilai di atas nilai pasar (overvalue). Dapat dikatakan pula telah terjadi transfer pengendalian aset dari akuisitee ke akuisitor sehingga total benefit dari abnormal return menunjukkan kinerja yang positif. 
Berdasarkan bukti-bukti di atas mengindikasikan bahwa pengambilalihan perusahaan menghasilkan positive gain, dimana shareholders perusahaan akuisitee dan perusahaan akuisitor tidak mengalami kerugian. Lebih jauh gain yang tercipta dalam pengambilalihan perusahaan tidak berasal dari penciptaan kekuatan pasar. Kesimpulan ini mendukung kesimpulan yang dikemukakan oleh Jensen and Ruback (1983:635).

\section{Rata-rata Abnormal Return setelah Akuisisi berdasarkan Faktor-faktor Akuisisi}

Berdasarkan faktor-faktor akuisisi menunjukkan bahwa setelah akuisisi rata-rata ROA, ROE dan abnormal return perusahaan mengalami perubahan. Abnormal return meningkat menjadi 0.0839. Hasil tersebut jika diuraikan terlihat dalam Tabel 3 berikut.

Tabel 3. Rata-rata Abnormal Return Setelah Akuisisi berdasarkan Katagori tertentu

\begin{tabular}{|l|r|}
\hline \multicolumn{1}{|c|}{ Katagori } & \multicolumn{2}{|c|}{ Abnormal Return } \\
\hline Seluruh akuisisi & 0.0839 \\
\hline Reaksi Manajemen Target & 0.1638 \\
Friendly & -0.0799 \\
Hostile & \\
\hline Sumber Dana Akuisisi & 0.1603 \\
Right Issue & 0.0305 \\
Kas & -0.1069 \\
Saham & \\
\hline Number of Bidder & -0.0393 \\
Single Bidder & 0.1232 \\
Multiple Bidder & \\
\hline Informasi Asimetris & \\
Undervalue & 0.4330 \\
Overvalue & -0.3491 \\
\hline Sifat Akuisisi & \\
Internal & -0.0393 \\
Eksternal & 0.1232 \\
\hline Bentuk Akuisisi & \\
Horizontal & -0.1682 \\
Vertikal & -0.0552 \\
Konglomerasi & 0.3406 \\
\hline Sunber: BEJ, data diolah kembali, 2000
\end{tabular}

Sumber: BEJ, data diolah kembali, 2000

\section{Pengaruh Faktor-faktor Akuisisi terhadap Abnormal Return}

Hasil analisis menunjukkan pengaruh yang berbeda antara faktorfaktor akuisisi dan Abnormal Return, baik secara simultan maupun secara parsial. Lebih jelasnya dapat dilihat pada Tabel 4. berikut ini. 
Tabel 4. Pengaruh Faktor-faktor Akuisisi terhadap Abnormal Return

\begin{tabular}{|l|c|c|c|c|c|c|c|}
\hline \multirow{3}{*}{$\begin{array}{c}\text { Variabel } \\
\text { terikat }\end{array}$} & \multicolumn{7}{|c|}{ Kariabel tidak terikat } \\
\cline { 2 - 7 } & $\begin{array}{c}\text { Rasio } \\
\mathbf{Q}\end{array}$ & Size & HF & CoI & NB & Al & \\
\hline CAR & 2.2100 & 18.8200 & 11.3700 & 0.9800 & 4.8900 & 59.1500 & 37.42 \\
\hline
\end{tabular}

Sumber : BEJ, data diolah kembali, 2000

Hasil analisis menunjukkan baik secara simultan maupun parsial faktor-faktor akuisisi berpengaruh positif terhadap CAR sebesar $37.42 \%$. Pengaruh secara parsial berturut-turut dari yang paling besar hingga paling kecil adalah $\mathrm{Al}=59.15$; Size=18.82; HF=11.37; NB=4.89;Rasio Q=2.21; dan $\mathrm{COI}=0.98$.

Pengaruh Rasio Q terhadap CAR sebesar 2.21 bermakna bahwa dengan nilai perusahaan di pasar yang cukup tinggi (di atas satu atau di atas rata-rata industri) menjadikan investor tertarik untuk mendapatkan saham perusahaan. Ketertarikan investor ini berdasarkan pertimbangan bahwa perusahaan cukup stabil untuk mengendalikan dan mengelola perusahaan dengan baik, termasuk perusahaan target. Hasil penelitian ini bersesuaian dengan penelitian Servaes (1991).

Sejalan dengan penelitian Peterson and Peterseon (1991) pengaruh positif Size sebesar $18.82 \%$ dapat dijelaskan bahwa perusahaan mampu meramu saham perusahaan target dan bidder untuk menghasilkan gain yang mampu menaikkan nilai kekayaan shareholders (maximum wealth of shareholders). Hasil ini di sisi lain bertentangan dengan penelitian Asquith, Bruner and Mullins (1983).

Pengaruh positif variabel HF sebesar 11.37 dapat dijelaskan bahwa perusahaan target merupakan bagian penghasil gain yang maksimal bagi bidder pasca akuisisi. Jika perusahaan target adalah perusahaan yang potensial, perlawanan manajemen target menjadikan daya tawar (bergaining position) atas harga saham menjadi meningkat. Bidder-bidder yang di pasar takeover berlomba untuk mendapatkan target, akibatnya harga sahampun meningkat. Gain dari transaksi inilah yang memberikan pengaruh positif bagi total return bidder pemenang. Hasil ini mendukung penelitian Servaes (1991), Kummer and Hoffmeister (1983) dan bertentangan dengan hasil penelitian Martin and McConnell (1991).

Pengaruh positif COI sebesar $0.98 \%$, meskipun kecil, bermakna bahwa dalam penelitian yang didominasi oleh akuisisi internal ini pengaruh bentuk pembiayaan tidak berbeda jauh antara pembiayaan melalui kas ataupun sumber lainnya. Akan tetapi bagaimanapun pembiayaan dengan kas untuk takeover lebih baik dan lebih berpeluang menghasilkan return yang positif. Hasil ini mendukung penelitian Peterson and Peterseon (1991). 
Pengaruh positif NB sebesar 4.89\% menunjukkan bahwa semakin banyak bidder semakin besar return yang dihasilkan. Return ini kemungkinan merupakan sumbangan saham target. Penelitian ini sesuai dengan yang dihasilkan Servaes (1991), Bradley, Desai and Kim dan Martin and McConnell (1991).

Pengaruh positif variabel Al sebesar 59.15 menunjukkan bahwa informasi yang tepat mengenai nilai target dan bidder menjadi sangat penting bagi kelanjutan penciptaan nilai saham kedua perusahaan. Jika manajer bidder mempunyai informasi yang cukup atau lebih baik tentang nilai asetnya dan aset target dibandingkan dengan investor lainnya, mereka akan membiayai akuisisi dengan saham, dengan keyakinan bahwa saham mereka overvalue. Hasil ini sejalan dengan penelitian Myer and Majluf (1984), Hansen $(1984,1987)$ dalam Amihud, Lev and Travlos (1990).

\section{Perbedaan Pengaruh Faktor-faktor Akuisisi Terhadap Abnormal Return Antara Akuisisi internal dan Akuisisi Eksternal}

Secara umum pengaruh pengaruh faktor-faktor akuisisi terhadap abnormal return berbeda antara akuisisi internal dan akuisisi eksternal. Terhadap abnormal return, Rasio Q, COI dan NB lebih berpengaruh pada akuisisi eksternal, sebaliknya Size dan HF lebih berpengaruh pada akuisisi internal. Variabel Al baik untuk akuisisi internal maupun eksternal tidak berbeda jauh pengaruhnya. Lebih lengkap dapat dilihat pada Tabel 5.

Tabel 5. Perbedaan Pengaruh Faktor-faktor Akuisisi terhadap Abnormal Return antara Akuisis Internal dan Akuisisi Eksternal

\begin{tabular}{|c|c|c|c|}
\hline \multicolumn{2}{|c|}{ Variabel tidak terikat } & Katagori & $\begin{array}{c}\text { Variabel terikat } \\
\text { CAR }\end{array}$ \\
\hline \multirow{12}{*}{ Koefisien Regresi } & \multirow{2}{*}{ Rasio Q } & Internal & 0 \\
\hline & & Eksternal & $-6.13 \mathrm{E}-02$ \\
\hline & \multirow{2}{*}{ Size } & Internal & -0.155 \\
\hline & & Eksternal & 0.113 \\
\hline & \multirow{2}{*}{ HF } & Internal & 0.959 \\
\hline & & Eksternal & 0.435 \\
\hline & \multirow{2}{*}{ COI } & Internal & $2.33 \mathrm{E}-02$ \\
\hline & & Eksternal & $-8.46 \mathrm{E}-02$ \\
\hline & \multirow{2}{*}{ NB } & Internal & 0 \\
\hline & & Eksternal & 0.518 \\
\hline & \multirow{2}{*}{$\mathrm{Al}$} & Internal & 0.246 \\
\hline & & Eksternal & 0.241 \\
\hline
\end{tabular}

Sumber: BEJ, data diolah kembali, 2000 


\section{KESIMPULAN}

Berdasarkan hasil pembahasan dan analisis terhadap permasalahan dan pengujian terhadap hipotesis yang dirumuskan sebelumnya, maka dapat disimpulkan sebagai berikut:

1. Terdapat penaikan abnormal return yang signifikan setelah akuisisi.

2. Secara simultan maupun parsial faktor-faktor akuisisi berpengaruh positif berturut-turut dari yang paling besar hingga paling kecil adalah Al, Size, HF, NB, Rasio Q dan COI.

3. Faktor-faktor akuisisi terhadap abnormal return memiliki pengaruh yang berbeda antara akuisisi internal dan akuisisi eksternal.

a. Rasio Q, COI, Size, dan HF lebih berpengaruh pada akuisisi yang bersifat internal

b. NB lebih berpengaruh pada akuisisi eksternal.

c. Al tidak berbeda pengaruhnya pada akuisisi internal maupun eksternal.

SARAN

1. Diperlukan penelitian lebih lanjut mengenai hal lain yang mempengaruhi keberhasilan akuisisi di luar variabel yang diteliti.

2. Perlu diperluas spektrum waktu atas data profitabilitas (lebih dari lima tahun).

3. Perusahaan-perusahaan yang melakukan akuisisi hendaknya mencermati dan mengelola faktor-faktor akuisisi agar mendapatkan hasil yang diharapkan.

\section{DAFTAR PUSTAKA}

Amihud, Yakov, Baruch Lev and Nicklolaos G. Travlos, (1990). Corporate Control and The Choice of Invesement Financing. The Case No. 2, June 1990 p. 6003-613.

Bapepam, (1989-1998). Indonesian Capital Market Directory. Jakarta.

Brealy, Richard A. And Stewart C Myers, (1996). Principles of Corporate Finance. McGraw-Hill Companies. Inc, New York.

Brown, T. David and Michael D Ryngaert, (1991). The Rule of Acquisition in Takeover, Taxes and Asymmetric Information. The Journal of Finance. Vol XLVI no. 2. June 1991, p. 653-669.

Constand, L. Richard, Lewis P. Freitas and Michael J. Sullivan, (1991). Factors Affecting Price Ratios and Market Values of Japanese Firm. FM Journal of The Financial Management Association Vol. 20/ Number 4 Winter. 1991, p. 68-79. 
Fama, F. Eugene and Merton H. Miller, (1972). The Theory of Finance. Dryden Press. Hindsdale, Illinois.

Gujarati, Damodar N, (1995). Basic Econometrics. Terjemahan oleh Sumarno Zain, Erlangga, Jakarta.

Haugen, Robert A., (1997). Modern Investment Theory. Fourth Edition, Prentice Hall, Inc. New Jersey.

Havinson, (1996). Pengujian Empiris terhadap Sinergi dalam Merger dan Akuisisi di Indonesia. Tesis UT, Jakarta.

Hiro Tugiman, (1999). Metode Penilaian Kinerja Perusahaan. Bandung.

Hitt, Michael A., (1997). Strategic Management. Terjemahan oleh Armand Hidiyanto, Cetakan pertama, Erlangga, Jakarta.

Ilya Avianti, (1994). Dampak Akuisisi dan Pencapaian Kinerja Perusahaan Go Public di PT BEJ. Tesis Unpad, Bandung.

Jensen, Michael C., and Richard S. Ruback, (1983). The Market for Corporate Control: The Scientific Evidence, Journal of Financial Economics, 1983, 11, 5-50, dalam The Modern Theory of Corporate Finance, Editor by Smith, Jr. W. Clifford. 1990, p. 593-638, Second Edition, Mc Graw-Hill, New York.

Jogiyanto, H.M., (1998). Teori Portofolio dan Analisis Investasi. Edisi Pertama, BPFE, Yogyakarta.

Jones, Charter P., (1991). Investment, Analysis and Management. Third Edition: John Wiley \& Sons, Inc. USA.

Livingstone, John Leslie, (1994). The Portable MBA-Keuangan dan Akunting. Alih bahasa oleh Dyah Ratna Permatasari, Binarupa Aksara, Jakarta.

M. Sudradjat Sutawidjaja dan H.R.A. Rivai Wirasasmita, (1997). Dasardasar Statistik Terapan. Bandung.

Martin, J. Kenneth and John J. McConnell, (1991). Corporate Performance, Corporate Takeovers, and Management Turnover. The Journal of Finance, Vol XLVI No. 2 June 1991, p.671-687.

Maulana Ibrahim, (1999). Program Restrukturisasi Perbankan dan Peranan Pengawasan Bank dalam Pelaksanaannya. Pengembangan Perbankan, Maret-April No. 76, hal 15-27.

Michael, Allen Israel Shaked and Yon Tay Lee, (1991). An Evaluation of Investment Banker Acqusition Advice: the Shareholders Perspec- 
tive. FM Journal of The Financial Management Association Vol 20/Number 2 Summer 1991. p.40-49.

Miranda S. Goeltom, (1998). Restrukturisasi: Kaitannya dengan Situasi Moneter Indonesia. Seminar Restrukturisasi Perbankan IndonesiaMerger, Konsolidasi dan Akuisisi, BI, Jakarta.

Mudradjat Kuncoro, (1997). Peluang dan tantangan Merger BUMN. Usahawan No. 11 tahun XXVI, hal 3-4.

Myer, C. Stewart and Nichlas S. Majluf, (1984). Corporate Financing and Investment Decisions When Firms Have Information That Investors Do Not Have. Journal of Financial Economics 13 (1984) 187221, dalam the Modern Theory of Corporate Finance, Editor by Smith, Jr.W.Clifford, 1990, p. 419-453, Second Edition, McGraw Hill, New York.

Napa J. Awat, (1999). Manajemen Keuangan-Pendekatan Matematis. PT Gramedia Pustaka Utama, Jakarta.

PDBI, (1995). Merger dan Acquisition di Indonesia, Jakarta.

Peterson, R. David and Pamela P. Peterson, (1991). The Medium of Exchange in Mergers and Acqusitions. Journal of Banking and Finance 15 (1661) p. 383-405.

Porter, Michael E., (1997). Strategi Bersaing-Teknik Menganalisis Industri dan Pesaing. Alih bahasa oleh Agus Maulana, Erlangga, Jakarta.

R. Agus Sartono, (1992). Manajemen Keuangan. Edisi 1. BPFE, Yogyakarta.

Servaes, Henry, (1991). Tobin's $Q$ and The Gains from Takeovers. The Journal of Finance, Vol. LXVI No. 1 March 1991. p. 409-419.

Sheperd, William G., (1990). The Economic of Industrial Organization. Third Edition, Prentice Hall-Englewood Cliffs, New Jersey.

Sudarsanam, P.S., (1999). The Essense of Mergers and Acquisitions. Edisi Pertama. Diterjemahkan oleh Rahmad Herutomo, Andi, Yogyakarta.

Sudjana, (1996). Metode Statistik. Edisi 6, Tarsito, Bandung.

Sutan Remy Syahdeirani, (1998). Merger, Konsolidasi dan Akuisisi, BI, Jakarta. 
Thakor, V. Anjan, (1991). Game Theory in Finance. FM Journal of The Finance Management Association, Vol. 20/ Number 1 Spring 1991. p.71-94.

Toni Prasentiantono, (1991). Beberapa Agenda Mendesak Pasca Likuidasi Bank, Pengembangan Perbankan Maret-April No. 76, hal 28-46

Weston, J. Fed \& Thomas E. Copeland, (1992). Manajemen Keuangan. Edisi Kedelapan, Jilid 2, Alih bahasa oleh A. Jaka Wasana MSM dan Kibrandoko MSM, Binarupa Aksara, Jakarta.

Weston, J. Fed \& Thomas E. Copeland, (1995). Manajemen Keuangan. Edisi Kesembilan, Jilid 1, Alih bahasa oleh A. Jaka Wasana MSM dan Kibrandoko MSM, Binarupa Aksara, Jakarta.

Weston, J. Fed, Kwang S. Chung dan Susan E.Hoag, (1990). Merger, Restructuring and Corporate Control, Prentice Hall, New York. 